\title{
Effect of presence of lifting pocket on the THD performance of a large tilting-pad thrust bearing
}

\author{
Michel FILLON ${ }^{1, *}$, Michal WODTKE ${ }^{2}$, Michal WASILCZUK ${ }^{3}$ \\ ${ }^{1}$ Institut Pprime, CNRS-Université de Poitiers-ISAE-ENSMA, Département Génie Mécanique et Systèmes Complexes, BP 30169, SP2MI, \\ 86962 Futuroscope Chasseneuil Cedex, France \\ ${ }^{2}$ Faculty of Mechanical Engineering, Gdansk University of Technology, Gdansk, Poland \\ ${ }^{3}$ Faculty of Mechanical Engineering, Gdansk University of Technology, Gdansk, Poland
}

Received: 23 April 2015 / Revised: 25 July 2015 / Accepted: 05 October 2015

(C) The author(s) 2015. This article is published with open access at Springerlink.com

\begin{abstract}
Hydrostatic assistance is a commonly used method to improve limited load carrying ability of tiltingpad thrust bearings during transient states of operation of vertical shaft hydro-generators. Despite of special hydraulic equipment (as pumps, valves, etc.), it also requires manufacturing of special recesses/pockets at pad sliding surfaces, into which oil is injected under high pressure. It allows to lift the rotor before start-up of the machine and form a hydrostatic film between pads and collar. There is a quite wide variety of geometry of recesses (shape, depth, and size) met in practical large bearing applications. The presence of a hydrostatic pocket (usually located in the sliding surface above the pivot area, where thin film, high oil pressure and temperature are observed) affects bearing performance under hydrodynamic operation.

In theoretical researches, there is an almost common practice not to include hydrostatic recess in thermohydrodynamic (THD) or thermoelastohydrodynamic (TEHD) analysis. This is probably due to the problems with obtaining solution for oil film geometry with pocket, the order of magnitude of the pocket depths being larger than gap thickness. In this paper, an attempt was taken to study the effect of lifting pocket on THD performance of a large tilting-pad thrust bearing of Itaipu power plant. Bearing performance was evaluated including recess shape for several cases of its depth. The results show that hydrostatic recess changes calculated bearing properties quite significantly, especially in vicinity of the pocket.
\end{abstract}

Keywords: lifting pocket; tilting-pad thrust bearing; THD regime; numerical simulations

\section{Introduction}

During the last decades, the studies on thrust bearings were numerous like those performed on the effects of size and thermoelastic deformations [1-3], on the thermal effects $[4,5]$ and on the spring supported pads [6, 7]. However, by the following, the bibliography will be focused on models used for large hydrodynamic bearings.

* Corresponding author: Michel FILLON.

E-mail: michel.fillon@univ-poitiers.fr

A preliminary version of this work was presented at the $2 \mathrm{nd}$ International Brazilian Conference on Tribology-TriboBr-2014, Foz do Iguaçu, Paraná, Brazil, 2014.
A large variety of hydrostatic pocket geometries exist in large thrust bearings - they seem to be designed so as not to deteriorate the bearing surface too much, but on the other hand to provide efficient oil supply and lifting capability, which depends on pocket size. Thus a pocket diameter is also a compromise between requirements of hydrostatic and hydrodynamic operation and to some extent a tendency of decreasing pocket size may be observed, accompanied by increased pressures in the hydraulic system. Some data from literature [8-12], showing design parameters of hydrostatic jacking systems of various hydrogenerators are presented in Table 1.

Various recommendations exist also as far as film 
Table 1 Comparison of hydrostatic systems of various hydrogenerators.

\begin{tabular}{ccccc}
\hline $\begin{array}{c}\text { Bearing outer/inner } \\
\text { diameters }(\mathrm{m})\end{array}$ & $\begin{array}{c}\text { Rotational speed } \\
(\mathrm{rpm})\end{array}$ & $\begin{array}{c}\text { Flow/pad } \\
(1 / \mathrm{min})\end{array}$ & $\begin{array}{c}\text { Pocket diameter }(\mathrm{mm}) \\
(\% \text { of pad width) }\end{array}$ & References \\
\hline $1.80 / 0.80$ & 187.5 & 1.00 & $75(15.0 \%)$ & HEPP Dychów [8] \\
$1.30 / 0.85$ & 600 & 1.35 & $75(33.0 \%)$ & PSPP Porąbka Żar [9] \\
$2.30 / 1.30$ & 500 & 1.42 & $85(17.5 \%)$ & HEPP Kopswerke [10] \\
$2.00 / 1.00$ & 500 & 5.00 & $125(12.5 \%)$ & {$[11]$} \\
$5.20 / 3.25$ & 92 & 4.70 & $170(17.5 \%)$ & HEPP Itaipu [12] \\
\hline
\end{tabular}

thickness and oil flow are concerned. According to Ref. [13], assumed film thickness should be proportional to square root of pad size and for the size of Itaipu power plant thrust bearing it should be $45 \mu \mathrm{m}$. Abramovitz [14] gives a more general recommendation of $50-250 \mu \mathrm{m}$. Assumed film thickness has a great influence on the system design, as the required pump output is proportional to the third power of the film thickness, so in order to increase film thickness twice, an eight-times increase of the pump output is necessary. According to the style of recesses there are also various forms, e.g., shown in the examples presented in Ref. [15]. There are pockets of annular style with a circular groove with the oil supply and a small depression in the inner area. The other common style is very shallow pocket with a flat bottom surface, some other manufacturers use a conical shape of the pocket.

In case of evaluation of the properties of large hydrodynamic thrust bearings, it is a common practice to omit hydrostatic pocket in the modeling. In fact, there are papers dealing with phenomena corresponding to pocket influence, but extremely rare it is included in thermoelastohydrodynamic (TEHD) models of large bearings. The only works known to the authors, which take into account this effect are papers of Pajączkowski et al. [10, 16], and Heinrichson [17]. Both authors include hydrostatic bearing depression of pad sliding surface in theoretical investigations of large thrust bearing properties under hydrodynamic mode of operation. In Refs. [10, 16], Kopswerk II (Austria) power plant hydrogenerator thrust bearing (outer diameter $2.3 \mathrm{~m}$ ) was analyzed under transient states. Relatively good agreement of calculated and measured pad temperatures was obtained, but this was only parameter measured and compared. In Ref. [17], Bieudron (Switzerland) hydrogenerator power plant thrust bearing was investigated (outer diameter $\sim 2.2 \mathrm{~m}$ ). In this case, film thickness measured by 4 distance sensors fixed to a pad, close to leading and trailing edge was compared to the calculated values. For the selected sensors good agreement was observed, but for sensors placed close to the pad trailing edge at inner and outer radius, measured values were significantly higher than the calculated ones. This discrepancy of the results could be explained with runner deflection, which was not included in theoretical analysis.

The aim of this work was to investigate theoretically how hydrostatic recess influences large hydrodynamic bearing properties under its hydrodynamic action. As an object of the analysis, Itaipu power plant hydrogenerator thrust bearing was selected (Fig. 1). This bearing, with its outer diameter equal to $5.2 \mathrm{~m}$, makes it one of the biggest thrust bearings which is under operation in the world. Bearing specific load is equal to $2.6 \mathrm{MPa}$ and rotational speed is $92 \mathrm{rpm}$. During commissioning of the machine, detailed measurements of the hydrogenerator were completed. Within machine testing program, all important bearing parameters were monitored, especially pad and collar temperatures, hydrodynamic pressures profiles and oil gap thickness profiles.
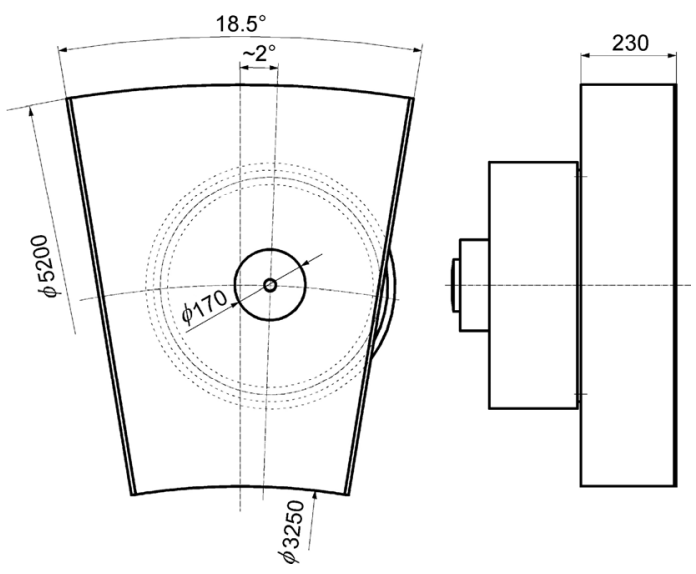

Fig. 1 Itaipu thrust bearing pad and support arrangement [18]. 
In previous works $[18,19]$, the authors completed TEHD analysis of Itaipu thrust bearing without including hydrostatic recess. Comparison of predictions and measurements revealed that there were results discrepancy, especially in the vicinity of the hydrostatic recess. That is why an attempt to include hydrostatic recess depression into analysis of Itaipu thrust bearing was taken. Additionally, it was decided to check the influence of the recess size on predicted bearing properties.

\section{Material and methods}

To reach the goal of this work, it was decided initially to use the bearing modelling which was applied with success in previous TEHD analysis of the Itaipu pad (without including the hydrostatic recess). Commonly, this model is based on the solution of Generalized Reynolds equation solved with the use of finite difference method, and can include all the most important bearing performance phenomena: pad tilting, thermal and elastic effects. Detailed description of the model can be found in Refs. $[18,19]$. The temperature in the lubricated film and in the pad is calculated by solving the $3 \mathrm{D}$ energy equation (i.e., the viscosity is varying across the film thickness) and the 3D heat transfer equation, respectively, using the finite difference method. Those equations have been established under the usual hypotheses: The lubricant is Newtonian and incompressible, and the flow regime is permanent and laminar. The main assumption is that the film thickness is very small compared to the other dimensions of the thrust bearing, i.e., the width and the length of the pads and so, the Generalized Reynolds equation can be employed to solve the problem. In addition, it is supposed that there is no slip at the film/pad and film/runner interfaces. The classical boundary conditions on pressure are applied: The pressure is equal to ambient pressure, which is the pressure reference, at the limit of the pads (inner and outer radii, at leading and trailing edges), i.e., the pressure is equal to zero. The temperature boundary conditions are the followings. The temperature at the inlet section, assumed to vary parabolically across the film thickness, is determined assuming all the hot oil carry-over from the previous pad is mixed to the fresh oil the bath between pads.
The film/runner interface temperature is assumed to vary radially while it is supposed to be constant in the tangential direction because of the shaft rotation: For each radial coordinate, the temperature is calculated based on thermal flux balance at the film/runner interface. At the film/pad interface, the fluid temperature is equal to the pad temperature and the heat flux continuity condition is applied. At the external surfaces of the pad, i.e., other than the active film/pad surface, the temperature is determined based on a free convection hypothesis: Global heat exchange coefficients are applied and a constant temperature $\left(39.3^{\circ} \mathrm{C}\right)$ is imposed in the oil bath surrounding the pad. These coefficients are varying according to the specific study done recently on the influence of heat convection coefficient on the predicted performance of a large tilting-pad thrust bearing [19]. In this study, the same values of the heat exchange coefficients were used. Low and uniform values were imposed at the back surface of the pad $\left(80 \mathrm{~W} /\left(\mathrm{m}^{2} \cdot \mathrm{K}\right)\right)$ and at the outlet pad wall $\left(100 \mathrm{~W} /\left(\mathrm{m}^{2} \cdot \mathrm{K}\right)\right)$. At the inlet pad wall and at the inner radius and outer radius pad walls, the heat convection coefficient varies considerably and linearly in the axial direction only (it remains constant in the radial direction): At the inlet pad surface, this coefficient varies from 120 (bottom of the pad) to $320 \mathrm{~W} /\left(\mathrm{m}^{2} \cdot \mathrm{K}\right.$ ) (top of the pad), at the inner radius pad surface, this coefficient varies from 20 (bottom of the pad) to $280 \mathrm{~W} /\left(\mathrm{m}^{2} \cdot \mathrm{K}\right)$ (top of the pad) and at the outer radius pad surface, this coefficient varies from 120 (bottom of the pad) to $420 \mathrm{~W} /\left(\mathrm{m}^{2} \cdot \mathrm{K}\right.$ ) (top of the pad). Additionally, more details on these boundary conditions on temperature can be found on Fig. 5 and in Table 3 of Ref. [19].

To include hydrostatic recess depression, oil gap geometry was modified in the area of pocket. It was assumed similarly as in Refs. [10,16] that recess has conical shape (truncated cone, vertex cone angle $175^{\circ}$ ) with nominal base diameter equal to $170 \mathrm{~mm}$, and nominal recess depth equal to $2 \mathrm{~mm}$. It was planned to study both influence of the recess depth and diameter on predicted bearing parameters.

During calculation process, it was proved that in order to obtain a converged solution, quite dense mesh grid had to be used. In previous calculations completed for Itaipu pad without presence of hydrostatic, 
recess grid $31 \times 49$ (radial $\times$ circumferential) was used . In the present analysis, the grid mesh was enlarged to $121 \times 121$ respectively (for some cases radial mesh was reduced to 51 divisions to shorten time of analysis). The choice of these grid meshes was done following the analysis of its influence on the main bearing characteristics (minimum film thickness, maximum film temperature, maximum hydrodynamic pressure, radial and tangential oil flow rates as well as friction torque). To ensure the prediction of accurate performance, the criteria of convergence are the following: $10^{-7}$ on the relative hydrodynamic pressure, $10^{-5}$ on relative load carrying capacity, $10^{-6}$ on relative temperature and $10^{-9}$ on relative tangential and radial rotations of the pad. Improved mesh allowed to achieve converged solution only for hydrostatic recess depth variation. Attempts carried out to analyze different recess diameter with the use of the mentioned model were not successful.

In these circumstances, it was decided to try to analyze influence of recess dimensions with the use of another method-Rigid Body Solver (RBS) implemented in CFX software [20]. This allows to carry out FSI analysis (Fluid Solid Interaction). In FSI technique both physical fields: fluid and solid interact exchanging loads between fields automatically. Limitation of RBS method is that interacting bodies can not deform under fluid or thermal loads, but can move freely, for example to reach equilibrium position. Rigid body can be defined within analysis as immersed solid or as set of surfaces. For the needs of this paper, 3D oil gap was modeled with the use of RBS (Fig. 2). Mesh density was specified to obtain a uniform grid, and $141 \times 101 \times 11$ divisions in radial $\times$ tangential $\times$ thickness were used. Calculations were completed for isothermal regime, with the assumed representative oil viscosity $\mu=0.018 \mathrm{~Pa} \cdot \mathrm{s}$ (Itaipu oil viscosity at $66^{\circ} \mathrm{C}$-average temperature of the pad in the results of thermohydrodynamic (THD) calculations). At the side of the oil gap, opening boundary condition was imposed. Upper wall of the model (touching the collar) was assumed as stationary wall with rotational speed equal to $n=92 \mathrm{rpm}$. Lower wall of the model (touching the pad) was assumed as a rigid body region. This wall can move in $z$ direction, and has rotational degrees of freedom (around $x$ and $y$ axis). At the pivot position at rigid body region of the

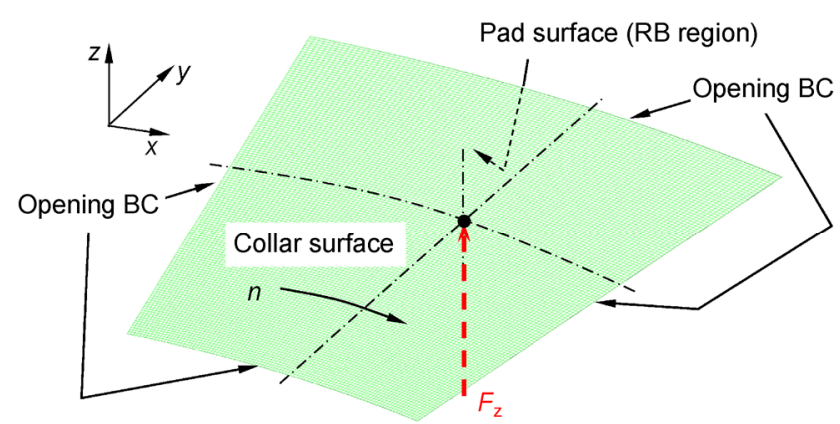

Fig. 2 Mesh of the oil gap used in RBS analysis (recess is not visible, due to large in plane dimensions comparing to model thickness).

model (pad/oil wall) vertical force $F_{z}=1.73 \mathrm{mN}$ was applied. This force is a representation of the bearing pad load, and causes rigid body wall movement and tilt (around $x$ and $y$ axis) to find its equilibrium position.

THD calculations were carried out for 5 different depths of hydrostatic recess: $30 \%, 50 \%, 70 \%, 85 \%$ and $100 \%$ of initial recess depth and nominal recess diameter.

Isothermal calculations with the use of RBS technique were completed for three recess depths: $30 \%$, $70 \%$ and $100 \%$ of initial recess depth (recess diameter in those cases was equal to $170 \mathrm{~mm}$ ) and three different recess diameter: $100 \%, 150 \%$ and $200 \%$ of initial recess diameter (recess depth in those cases was equal to $2 \mathrm{~mm}$ ). Additionally, one case without the recess was also calculated.

\section{Results and discussion}

Results of calculations are presented in form of profiles, to make it easy to compare them and find differences in calculated bearing parameters. Additionally, some selected bearing parameters are also shown as contour plots.

\subsection{THD results}

THD calculations were carried out for different recess depth. Extreme values of calculated parameters were collected in Table 2.

The largest maximum oil pressure $p_{\max }$ was calculated in case of smallest recess depth $(5.97 \mathrm{MPa}, 30 \%$ of nominal depth). Increase of recess depth caused decrease of calculated maximum oil pressure, to its minimum value equal to $5.6 \mathrm{MPa}$ for $2 \mathrm{~mm}$ recess depth. 
Table 2 Comparison of calculated bearing parameters for different recess scaling, THD regime.

\begin{tabular}{ccccccc}
\hline & & \multicolumn{5}{c}{$h$ scale } \\
\cline { 3 - 7 } THD & Unit & \multicolumn{3}{c}{ mesh $121 \times 121$} & mesh $51 \times 121$ \\
\cline { 3 - 7 } & & $30 \%$ & $50 \%$ & $70 \%$ & $85 \%$ & $100 \%$ \\
\hline$p_{\max }$ & $\mathrm{MPa}$ & 5.97 & 5.76 & 5.70 & 5.62 & 5.60 \\
$T_{\max }$ & ${ }^{\circ} \mathrm{C}$ & 81.8 & 81.4 & 81.1 & 81.7 & 81.6 \\
$h_{\min }$ & $\mu \mathrm{m}$ & 72.7 & 73.3 & 73.9 & 72.5 & 72.6 \\
\hline
\end{tabular}

In case of maximum pad sliding surface temperature $T_{\max }$ the trend is not constant. Increase of recess depth leads to a small decrease of calculated maximum temperature. But for cases of $85 \%$ and $100 \%$ of the recess depth, calculated maximum temperature of the pad was higher. This is probably caused by the change of grid density (from $121 \times 121$ on $51 \times 121$ ). Similar results inconsistency is observed also in calculations of minimum oil gap thickness $h_{\min }$. Slightly larger minimum film thickness was calculated for deeper recesses, but change of mesh density disturbed this trend.

In Fig. 3, results of THD calculations for three recess depths in form of contour plots are shown. Differences in calculated parameters are not so significant, but presence of hydrostatic recess is clearly visible in the contours of hydrodynamic pressure and temperature of pad sliding surface.

Differences in calculated bearing parameters can be more easily observed in Fig. 4, where profiles of oil gap pressure, oil gap thickness and pad sliding temperature at pad mean radius are compared. Comparing oil gap pressure profiles it is clearly visible that shallow recess $(30 \%)$ influences the pressure profile less than deep recess $(100 \%)$. In case of shallow recess, pressure increased continuously, even in the zone of hydrostatic recess. While for deep recesses (85\% and $100 \%)$ there is an area with almost constant pressure in the pocket (form of "plateau").

Comparing calculated oil gap profiles, one can observe that shallow recess leads to lower circumferential pad tilt. On the opposite, deep recess caused the largest pad tilt. Recess depth had almost no influence on minimum film thickness calculated with the use of THD model.

Concerning temperature profiles at pad mean radius, irrespective of recess depth, temperature profile is
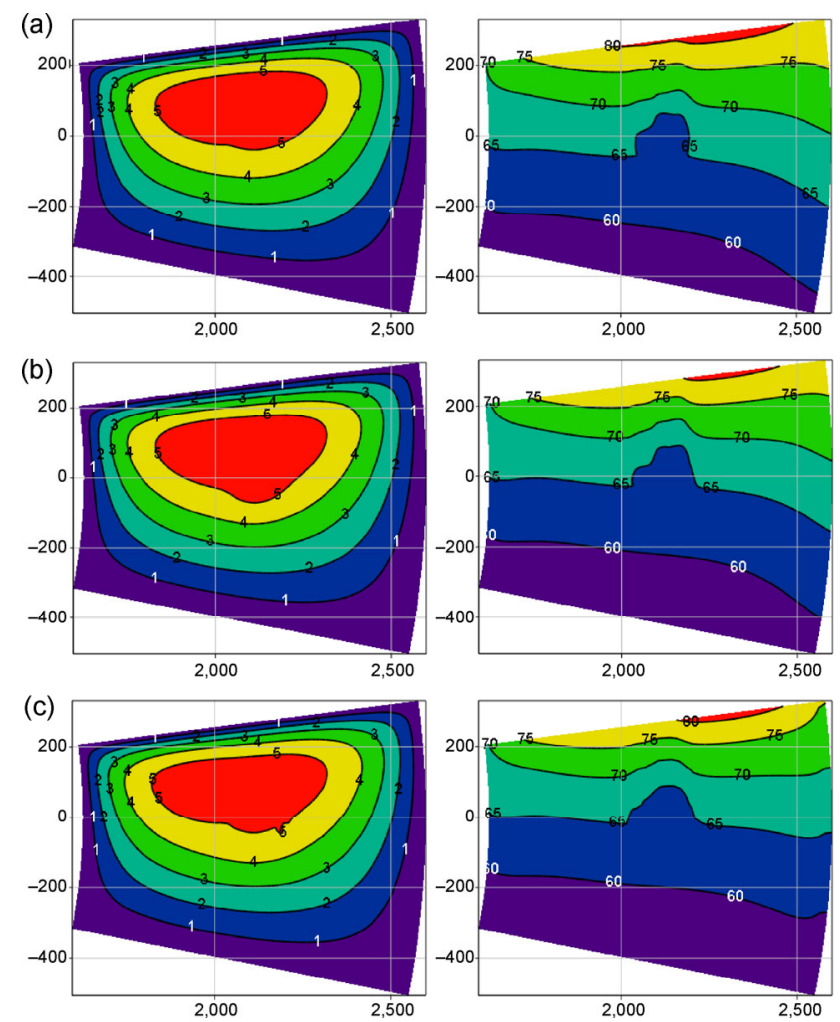

Fig. 3 Contour plot of hydrodynamic pressure (MPa) (left-hand column) and pad sliding surface temperature $\left({ }^{\circ} \mathrm{C}\right.$ ) (right-hand column); (a) for $30 \%$ of recess depth, (b) for $70 \%$ of recess depth, and (c) for $100 \%$ of recess depth.

very similar. The highest temperature of pad sliding surface was calculated for the case with shallow recess (30\%), the smallest for the case of deep recess (100\%). Temperature of the pad increased from the inlet to the pad to the beginning of the recess. Then, in the area of the pocket, small temperature drop was observed for all analyzed cases of recess depths. In the recess area, temperature increased slightly, and approaching recess outlet significant temperature increase was calculated. In the area between recess and pad outlet, constant temperature gradient can be seen for all analyzed cases.

\subsection{Rigid body solver solution-isothermal case}

Isothermal calculations were carried out for different recess depths and recess diameters. Extreme values of calculated parameters were collected in Table 3.

Analyzing data collected in Table 3, clear trends are visible. Presence of the shallow recess increased maximum hydrodynamic pressure comparing to case without recess (h scale $0 \%$ ). For deeper recesses, 

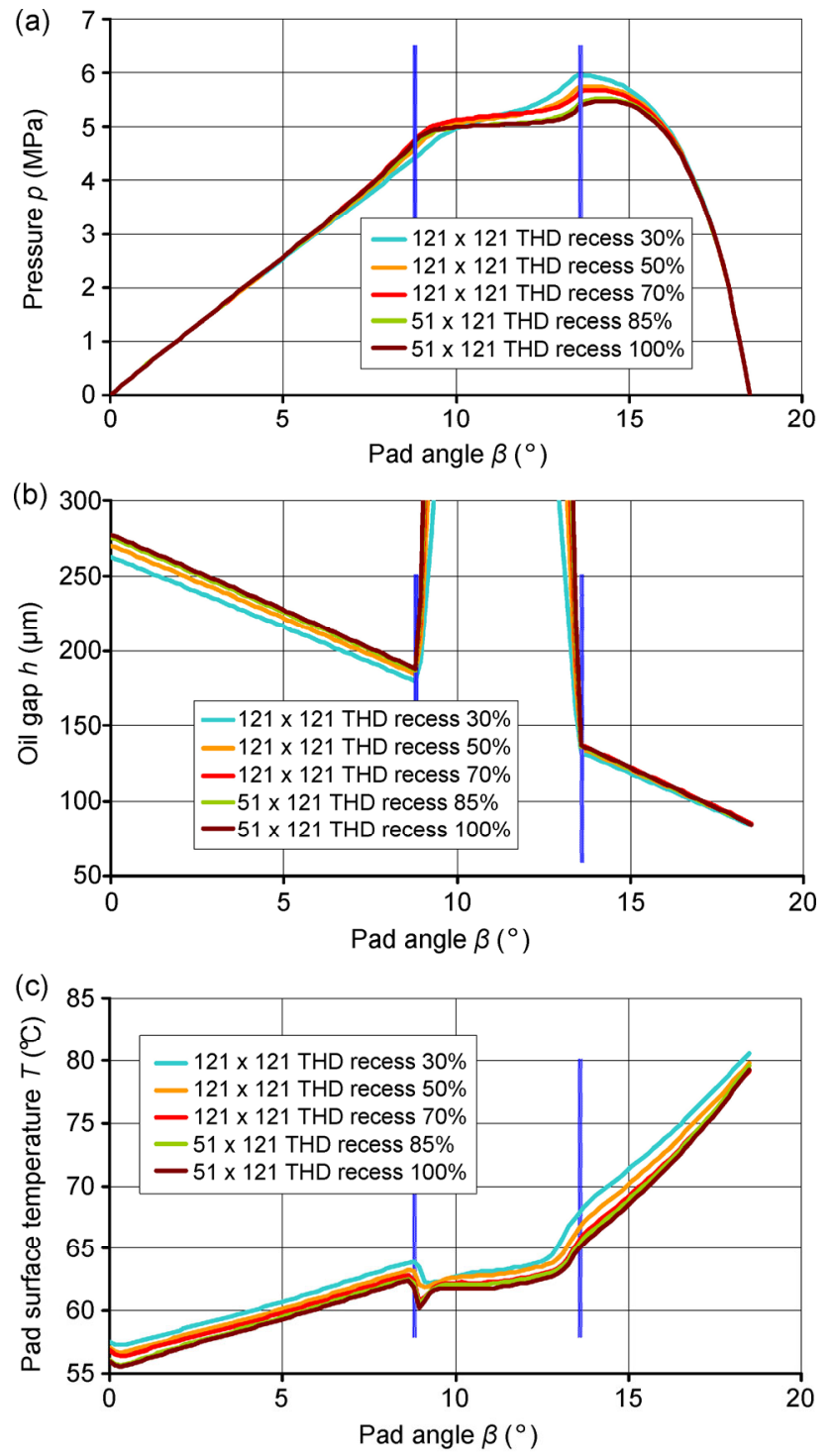

Fig. 4 THD results of Itaipu pad parameters profiles at mean pad radius as a function of recess depth; (a) oil gap pressure (MPa), (b) oil gap thickness $(\mu \mathrm{m})$, and (c) pad sliding surface temperature $\left({ }^{\circ} \mathrm{C}\right)$.

Table 3 Comparison of calculated bearing parameters for different recess scaling, isothermal regime.

\begin{tabular}{|c|c|c|c|c|c|c|c|}
\hline \multirow{2}{*}{$\begin{array}{c}\text { RBS } \\
\text { isothermal }\end{array}$} & \multicolumn{2}{|l|}{$d$ scale } & \multicolumn{3}{|c|}{$100 \%$} & \multirow{2}{*}{$\frac{150 \%}{100 \%}$} & \multirow{2}{*}{$\frac{200 \%}{100 \%}$} \\
\hline & $h$ scale & $0 \%$ & $30 \%$ & $70 \%$ & $100 \%$ & & \\
\hline$p_{\max }$ & $\mathrm{MPa}$ & 5.85 & 6.02 & 5.71 & 5.63 & 5.33 & 5.17 \\
\hline$h_{\min }$ & $\mu \mathrm{m}$ & 83.4 & 82.1 & 81.5 & 81.2 & 78.8 & 74.2 \\
\hline
\end{tabular}

maximum hydrodynamic pressure was calculated smaller than for shallow recesses. What seems interesting, for cases with $70 \%$ and $100 \%$, maximum hydrodynamic pressure was calculated smaller than in case without hydrodynamic recess. Concerning minimum oil gap thickness, it was calculated the smallest for deep recesses, and highest for case without recess. However, in this case, differences were not significant $(\sim 2 \mu \mathrm{m})$.

Comparing obtained results for different recess diameters, one can see that larger recess diameter $(200 \%)$ caused reduction in maximum oil gap pressure, and also in minimum film thickness comparing to case with nominal pocket diameter (d scale $100 \%$ ).

In Fig. 5, contour plots of calculated hydrodynamic pressure for different recess depths and diameters are shown. The same contour scale were used for all graphs, to make it easy to compare the results. Depression of the hydrostatic recess has a significant influence on hydrodynamic pressure profile, and is visible as an isobar shape change in contour plots shown in Fig. 5.

(a)

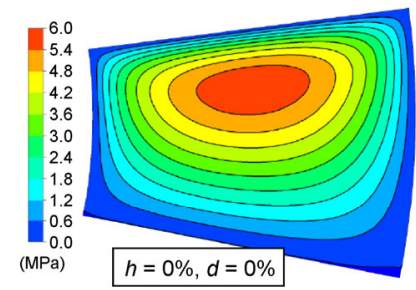

(b)

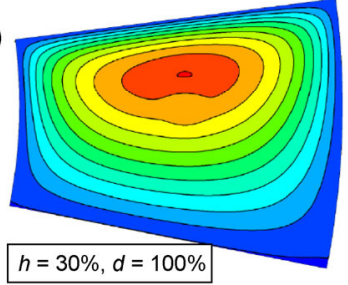

(c)

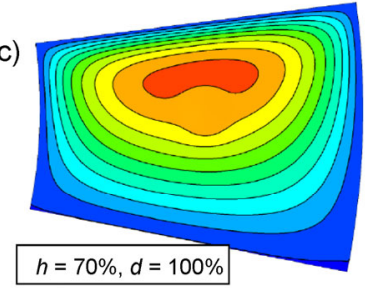

(d)

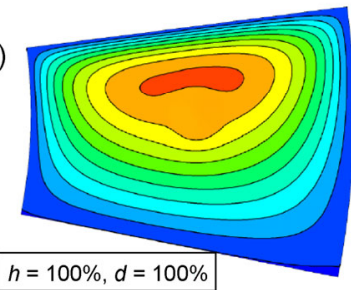

(e)
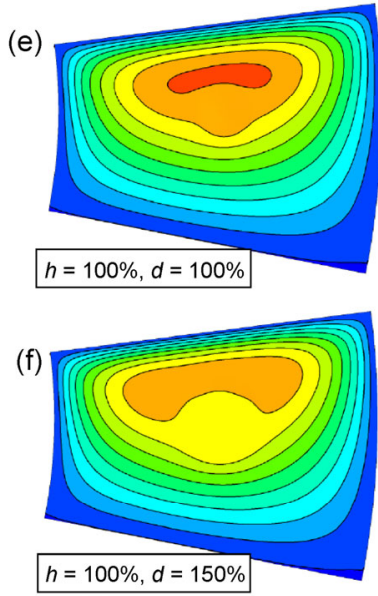

(g)

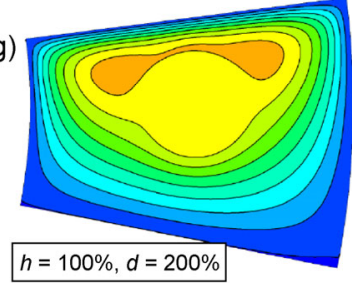

Fig. 5 Contour plots of hydrodynamic pressure (MPa) obtained for isothermal calculations; (a) pad without recess, (b)-(d) for recess depth variation (left-hand column), and $(\mathrm{e})-(\mathrm{g})$ for recess diameter variation (right-hand column). 
In Figs. 6 and 7, calculated at mean pad radius profiles of hydrodynamic pressure and oil gap thickness were compared for different recess dimensions.

Comparing oil gap pressure (Figs. 6(a) and 7(a)), stronger influence on pressure profile had variation of the recess diameter then its depth. In case of variation of recess depth, the same trends were observed as for THD calculations (see Fig. 4(a)). The highest hydrodynamic pressure was calculated for shallow recess, the smallest for deep recess. In case of oil film thickness calculated with the use of isothermal regime, same trends in influence of recess depth on oil film thickness was noticed as for THD results. The smallest pad tilt was calculated for shallow recess (30\%), the highest for deep recess. Nevertheless, what should be mentioned, differences in tangential oil film profiles were not significant.
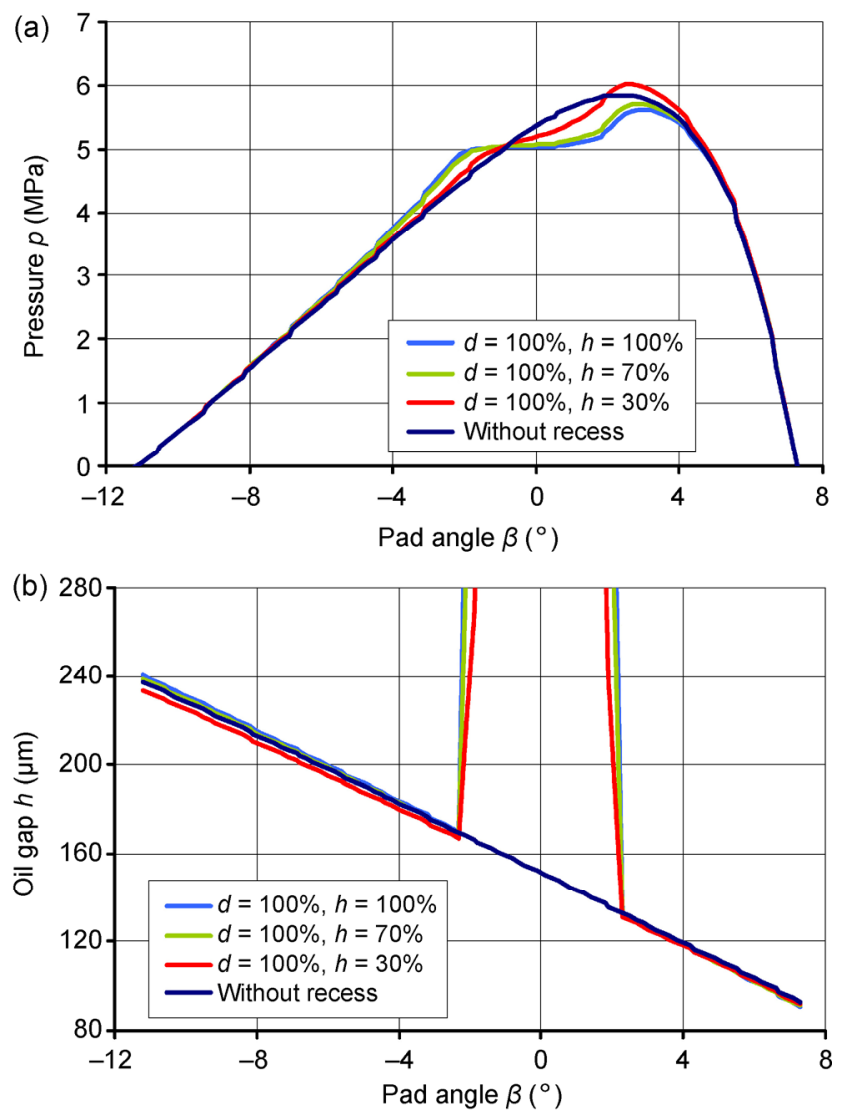

Fig. 6 Isothermal results of Itaipu pad parameters profiles at mean pad radius as a function of recess depth variation (depth of the recess changed in range between $30 \%$ and $100 \%$ of nominal pocket depth); (a) oil gap pressure (MPa), and (b) oil gap thickness $(\mu \mathrm{m})$.
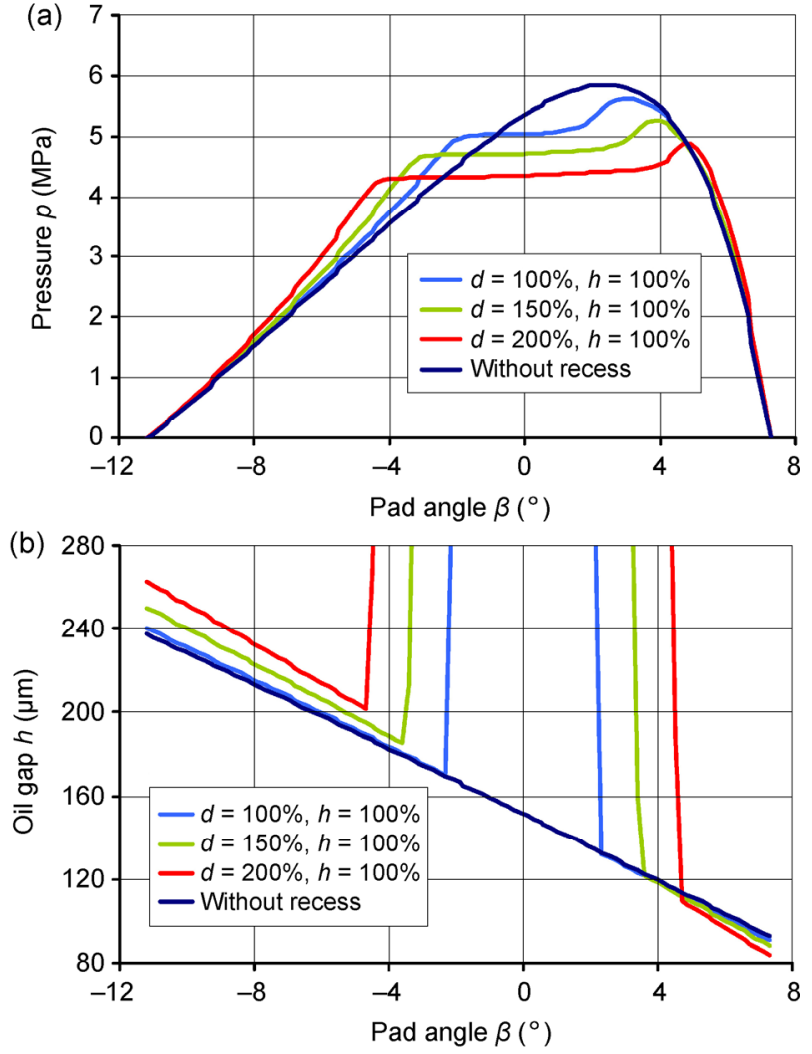

Fig. 7 Isothermal results of Itaipu pad parameters profiles at mean pad radius as a function of recess diameter variation (diameter of the recess changed in range between $100 \%$ and $200 \%$ of nominal pocket diameter); (a) oil gap pressure ( $\mathrm{MPa}$ ), and (b) oil gap thickness $(\mu \mathrm{m})$.

In case of the results obtained for different recess diameters - it had stronger influence on calculated pad tilt than the recess depth. Increased recess diameter resulted in larger pad tangential tilt and smaller oil gap thickness at pad outlet. Concerning pressure profiles, in all analyzed cases of recess diameter, in the area of the recess pressure plateau was observed. What is characteristic, close to the recess end pressure rise was calculated.

\section{Conclusions}

In this paper, a modelling of lifting pockets in tiltingpad thrust bearings has been presented in both isothermal and thermohydrodynamic regimes. The influence of pocket depth and pocket size on the main bearing characteristics has been analyzed. The main conclusions are the following:

- Significant problems with the solution convergence 
were caused by including a hydrostatic pocket into theoretical analysis of the thrust bearing.

- The presence of a lifting pocket has an significant effect on both pressure and temperature fields on the pad. In the pressure field, a plateau is observed in the pocket and a pressure jump is noticeable at pocket trailing edge. In the temperature field, a general small decrease and remarkable drop at leading edge of the pocket are noted.

- Maximum pressure and maximum temperature are reduced.

- The pad tilt angle is increased compared to the operation without a lifting pocket. Thus, minimum film thickness decreases.

- The influence of the pocket increases with the increase of depth and size of the pocket.

Future work will concern the analysis of the influence of the lifting pocket on the TEHD performance of large tilting-pad thrust bearings and the comparison of the numerical results with the experimental data.

Open Access: This article is distributed under the terms of the Creative Commons Attribution Noncommercial License which permits any noncommercial use, distribution, and reproduction in any medium, provided the original author(s) and source are credited.

\section{References}

[1] Ettles C M. Size effects in tilting pad thrust bearings. Wear 59(1): 231-245 (1980)

[2] Ettles C M, Anderson H G. Three-dimensional thermoelastic solutions of thrust bearings using code Marmac 1. ASME J Tribol 113(2): 405-412 (1991)

[3] Kawaike K, Okano K, Furukawa Y. Performance of a large thrust bearing with minimized thermal distortion. ASLE Trans 22(2): 125-134 (1979)

[4] Kuhn E C. Largest thrust bearings are water cooled. Power: 100-101 (1971)

[5] Chambers W, Mikula A. Operational data for a large vertical thrust bearing in a pumped storage application. STLE Trans 31(1): 61-65 (1988)

[6] Ettles C M. Some factors affecting the design of spring supported thrust bearings in hydroelectric generators. ASME J Tribol 113(3): 626-632 (1991)
[7] Yuan J H, Medley J B, Ferguson J H. Spring-supported thrust bearings used in hydroelectric generators: Comparison of experimental data with numerical predictions. Tribol Trans 44(1): 27-34 (2001)

[8] Wodtke M. Evaluation of design parameters of a hydrostatic jacking system of a hydrogenerator. (in Polish). Tribologia 196(4): 339-347 (2004)

[9] Dąbrowski L, Wasilczuk M. Influence of hydrostatic pump operation period on performance of a thrust bearing of a 125 MW pump-turbine. Mécanique \& Industries 5(1): 3-9 (2004)

[10] Pajaczkowski P, Schubert A, Wasilczuk M. Modeling Transient states of large hydrodynamic thrust bearings. In 7th EDF/LMS Poitiers Workshop on Operational limits of bearings: Improving of performance through modeling and experimentation, Poitiers, France, 2008: 1-8.

[11] Ettles CM, Seyler J, Bottenschein M. Some Effects of start-up and shut-down on thrust bearing assemblies in hydro-generators. J Tribol 125(4): 824-832 (2003)

[12] Generation Equipment Itaipu Hydroelectric Project - Alstom. www.alstom.com, 2015.

[13] Peeken H, Benner J. Calculations of radial and thrust hydrostatic bearings. (in German). Publication of Th. Goldschmidt AG 61 2/84, 1984.

[14] Abramovitz S. Using hydrostatic bearings as "lifts" in hydroturbines. Hydro Review 19: 38-47 (2000)

[15] Wasilczuk M, Wodtke M, Dąbrowski L. Large hydrodynamic thrust bearings and their application in hydrogenerators. In Encyclopedia of Tribology. Wang Q J \& Chung Y W (Eds.). Springer, 2013: 1912-1926.

[16] Pajączkowski P, Schubert A, Wasilczuk M, Wodtke M: Simulation of large thrust-bearing performance at transient states, warm and cold start-up. J Eng Tribol 228(1): 96-103 (2014)

[17] Heinrichson N. On the design of tilting-pad thrust bearings. Ph.D. Thesis. Lyngby: Technical University of Denmark, 2006.

[18] Wodtke M, Schubert A, Fillon M, Wasilczuk M, Pajączkowski P. Large hydrodynamic thrust bearing: Comparison of the calculations and measurements. J Eng Tribol 228(9): 974-983 (2014)

[19] Wodtke M, Fillon M, Schubert A, Wasilczuk M. Study of the influence of heat convection coefficient on predicted performance of a large tilting-pad thrust bearing. J Tribol 135(2): 1-11 (2013)

[20] Ansys, Release 13 documentation, SAS IP, Inc., 2010. 


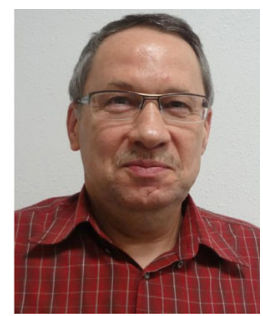

Michel FILLON. He received his Ph.D. degree in mechanical engineering from University of Poitiers, France, in 1985. He is a CNRS Director of Research at the Pprime Institute. From 2002 to 2010, he has been Manager of the "Lubricated Contact Mechanics" Research Group. His current research interests are both experimental and theoretical investigations of hydrodynamic journal and thrust bearings. He is a Fellow of ASME and STLE. From 2006 to 2008, he was the Chair of Research Committee of ASME Tribology Division. He is currently coEditor-in-Chief of Tribology International and has been an Associate Editor of ASME Journal of Tribology (from 2003 to 2009). Dr. Michel Fillon is a member of the Annual Meeting Program Committee of STLE and he is organizing the EDF/Pprime Workshop on Journal and Thrust Bearings since 2002. 